\title{
Computational Fluid Dynamics of Heat Transfer in Stirred Tank Reactors
}

\author{
Chaitanya Moholkar ${ }^{1}$, Punit Gharat ${ }^{1}$, Vivek Vitankar ${ }^{2}$, Channamallikarjun Mathpati ${ }^{1}$, and \\ Jyeshtharaj Joshi ${ }^{1}$ \\ ${ }^{1}$ Institute of Chemical Technology \\ ${ }^{2}$ Fluidimensions
}

September 25, 2021

\begin{abstract}
In the present work, computational fluid dynamics study of stirred tanks of three sizes (20L, 400L and 5000L) provided with helical coils has been carried out. Various design parameters (impeller diameter, type and clearance) and operational parameters (Reynolds Number and Power per unit volume) have been varied and their effect on process side heat transfer coefficient has been studied. CFD model is validated with experimental work of Cummings and West[9] and in house experimentation. Design settings of $\mathrm{D} / \mathrm{T}=0.5, \mathrm{C} / \mathrm{T}=0.33$ for $\mathrm{PBTD} 450$ resulted in maximum heat transfer $(5440 \mathrm{~W} / \mathrm{m} 2 \mathrm{~K}$ for $\mathrm{P} / \mathrm{V}=1000 \mathrm{~W} / \mathrm{m} 3)$. For constant RPM and constant D/T (Constant Reynolds Number), Increasing the power number of impeller increased process side HTC at the cost of increased power requirement (decreasing efficiency). In such cases, proper selection of impeller system needs to be made based on the requirements of heat removal and optimizing parameters such as product yield, product quality etc.
\end{abstract}

\section{Hosted file}

ISCRE_Manuscript_Draft_FINAL_12.docx available at https://authorea.com/users/437270/articles/ 539024-computational-fluid-dynamics-of-heat-transfer-in-stirred-tank-reactors 